\title{
Analysis of Elementary School Teachers' Perceptions of Mathematics-Focused STEAM Education in Korea
}

\author{
Min Kyeong Kim ${ }^{1 *}$, Ji Young Lee ${ }^{1}$, Hyeonsu Yang ${ }^{1}$, Juhyun Lee ${ }^{1}$, Ji Na Jang ${ }^{1}$, Seon Joo Kim ${ }^{1}$ \\ ${ }^{1}$ Ewha Womans University, SOUTH KOREA
}

Received 23 July 2018 - Revised 17 December 2018 • Accepted 1 February 2019

\begin{abstract}
The purpose of this study is to examine the perceptions of elementary school teachers and the conditions within which they teach. This study is expected to contribute to the preparation for the new technology demands of our rapidly changing society and the recent changes made to the 2015 Revised National Curriculum aimed at Fostering Creative-Convergence Human Resources in Korea. It is primarily expected to contribute to the application of the Science, Technology, Engineering, Arts and Mathematics (STEAM) education and Math-Focused STEAM education. For this purpose, we surveyed 273 teachers of 24 public schools in Seoul and Gyunggido area. The results showed that teachers recognized 'convergence' in STEAM education either as an 'integrated approach' in which specific subjects or topics are taught together or as a 'convergent approach' to teach together and further to a new one. In addition, positive responses were shown towards Math-Focused STEAM education in terms of its effectiveness on the education and needs of the students. The most significant problem in terms of the school environment was the lack of preparation time provided, materials, and educational resources. This study is expected to support the increased application of Math-Focused STEAM education in the field, and thus to expand the knowledge embodied in the subject of mathematics.
\end{abstract}

Keywords: STEAM education, math-focused STEAM education, elementary school teachers' perception

\section{INTRODUCTION}

It is important to determine the essential requirements for the education curriculum in society in the 21st century, and to contribute to the discourse on the contents and methods of school education required today. The rapidly changing social and technological changes that have taken place in recent decades have raised fundamental questions such as "What kind of ability do people need from these future generations?" Additionally, many changes are taking place globally throughout the educational world in attempts to answer these questions.

In 1997, the Organization for Economic Cooperation and Development (OECD) highlighted the development of core competencies for future society in the DeSeCo Project. The OECD presented 'Use tools interactively', 'Interact in heterogeneous groups', and 'Act autonomously' as Key Competencies in Three Broad Categories, which provided an opportunity to re-examine the educational significance of creativity and problem solving (OECD, 2003). The OECD's competence-centered approach has allowed for the opportunity to reorganize curricula so as to center on competencies, rather than being subject-based. Because traditional classes emphasized the acquisition of subject knowledge, it was necessary to make a general change in education toward a system that handles various subjects in an integrated manner in order to develop abilities. While competency-based curricula are present all over the world, Korea's 2015 Revised National Curriculum has specifically undergone a major change into a competency-based curriculum. The intention of the 2015 Revised National Curriculum was to foster the integration of creative talents to contribute new value by combining the humanities subjects with science and technology. The

(C) 2019 by the authors; licensee Modestum Ltd., UK. This article is an open access article distributed under the terms and conditions of the Creative Commons Attribution License (http://creativecommons.org/licenses/by/4.0/). 《mkkim@ewha.ac.kr ( ${ }^{*}$ Correspondence) $\nabla$ roana@naver.com $\nabla$ gustn6217@naver.com 


\section{Contribution of this paper to the literature}

- In this study, 273 elementary teachers in Korea were surveyed to analyze their perceptions and awareness of STEAM education.

- This paper highlights the implications for the education field regarding this new approach by examining the teachers' understanding of not only STEAM education but also Math-Focused STEAM education.

- This paper shows a positive correlation between the perception of Math-Focused STEAM education and the effectiveness of Math-Focused STEAM education.

intention is to enhance creativity and create new knowledge by matching personalities with various areas of knowledge (Ministry of Education [MOE], 2015). In Korea, through continuous revision of the curriculum, the scope and contents of mathematical literacy and learner knowledge have gradually been transformed into a learnercentered mathematics approach which emphasizes the learner as the key of learning mathematics based on constructivism.

Meanwhile, in March 2016, the emergence of the Alpha model, which had a significant impact not only on Korean society but also globally, provided an opportunity to check the current status of education in terms of its ability to develop leaders of our country's future generations. The implications of the fourth revolution in the emergence of artificial intelligence and robots at the Davos Forum in 2016 and 2017 also signaled a rapidly changing social transformation. On the other hand, in the educational field, current students are cautiously considering whether they are being provided with a road map for the 'talent of the future society demanding various abilities' (MOE, 2015) and whether their education reflects the rapidly changing social and technological issues. Today's schools need to focus specifically on 'future mathematics topics' like big data, programming, virtual reality, 3D printing, and Information and Communications Technology (ICT) in order to face the inevitable upheaval of the fourth revolution (Na, Park, Kim, Kim, \& Lee, 2018), especially in terms of the direction of mathematics education.

While in the past the focus was on reflecting technical things as educational tools, it has recently become important to reflect these changes through philosophy, teaching methods, learning, and evaluation (Askhamov, Konysheva, \& Gapsalamov, 2016; Gresnigt, Taconis, Keulen, Gravemeijer, \& Baartman, 2014; Hennessy, 2006; Pavlekovic, Kolar-Begovic, \& Kolar-Super, 2013). The current effort to integrate technology into the classroom is being discussed in consideration of the increased access to the integration of technology and lessons, based on the TPACK (Technological Pedagogical Contents Knowledge) framework (Kim, 2017; Yigit, 2014). In addition, 'embodied cognition', which is a cognitive view reflected in artificial intelligence, has also recently been attracting attention in education. The constructivist context that emphasizes 'doing' reflects the dynamics of change in that knowledge can be perceived in various ways through various environments and active responses, beyond the simple meaning of remembering knowledge (Osgood-Campbell, 2015; Stolz, 2015). In particular, technological changes in mathematics education lead to more interactive participation, visualization, and direct experience (Pavlekovic, Kolar-Begovic, \& Kolar-Super, 2013).

Historically, the content and pedagogical methods of school math were systematized as the mathematics curriculum developed, which led to the incorporation of the topic of cognition into the math subject (Nemirovsky \& Ferrara, 2009; Nunez, Edwards, \& Matos, 1999), which should be discussed in the context of meaningful teachinglearning. In mathematics education, meaningful teaching-learning requires various connections, both internally and externally (Berlin \& White, 1995; NCTM, 1989). Mathematics education has long pursued more "realistic" education, which has been too much for institutional norms of education, but reality and education have recently shown divergence (FitzSimons \& Boistrup, 2017). As recent social change has brought attention to improving the quality of education and as the demand for quality in education has increased, interdisciplinary approaches have been increasingly studied in the field of education (Rennie, Venville, \& Wallace, 2012). In Korea, 'STEAM education' is used officially in this interdisciplinary point of view when viewing definition 'convergence of Science, Technology, Engineering, Art, Mathematics' which was set by Korea Foundation for the Advancement of Science and Creativity (Han \& Kwon, 2017; Lee \& Kim, 2012; Woo \& Yoo, 2013). Furthermore, studies on convergence education are actively being carried out (Hwang et al., 2017; Noh, Kim, Yeom, Lee, \& Kim, 2018; Oh, 2018; Ryu, Lee, Yoon, \& Kim, 2018; Shin, 2018).

The beginning of STEAM education can be traced back to STS in USA in the 1980s, followed by MST, STEM, and finally STEAM (Kang, 2015). STEAM stands for 'Science, Technology, Engineering, Arts, and Mathematics'. It generally means that two or more subjects are integrated or related in teaching-learning, and it is not aimed at perfect students across all subjects. This is because it is concerned with the various abilities and emotional attitudes that students can form through education (Kang, 2015). In other words, STEAM education can be regarded as an educational tool that can accommodate various educational changes beyond the subjects themselves.

So, how is the state of STEAM education in Korea? In Korea, the education field has been addressing the need for integration/convergence, led by science departments, in earnest since 2011 (Baek et al., 2011). As the 
development of technology has brought "convergence" into the realm of education, the subject of science has come to prominence in a way that leads STEAM education (Baek et al., 2012; Sim, Lee, \& Kim, 2015). This is consistent with the fact that many studies on STEAM education have been mainly conducted in scientific subjects. To date, STEAM education related research has been largely based on program development (Lee \& Yoon, 2014), model development for application (Kim, 2011; Kim, Chung, Woo, \& Lee, 2012; Rhie, Kim, \& Kim; 2015), and surveying teachers' perceptions (Han \& Lee, 2012). However, in order to effectively apply STEAM education, the perceptions and demands of in-service teachers on STEAM education need to be continually examined. However, many previous studies have been conducted on teachers whose subjects of interest include science (Chae \& Noh, 2015; Han \& Lee, 2012; Jung, Jeon, \& Lee, 2015; Kwon \& Ahn, 2012; Kwon \& Na, 2010; Lim, Kim, \& Lee, 2014; Lim \& Oh, 2015; Lee, Park, \& Kim, 2013; Shin, 2013; Shin \& Han, 2011; Son, Jung, Kwon, Kim, \& Kim, 2012). This is also due to the fact that STEAM education is treated as a part of the science curriculum, and that STEAM training is mostly directed at science teachers. Although STEAM education can be applied to various subjects, there are limitations in that some aspects of STEAM education are only employed in certain subjects in Korea.

In Korea, the recently published 2015 revised mathematics curriculum discussed the 'creativity-fusion' capability in mathematics (MOE, 2015). This capability emphasizes the importance of convergence education (STEAM education) in mathematics as well as the connections to real life contexts within mathematics. However, mathematics was used for tooling in STEAM education (Ju, Song, \& Moon, 2013) and it was not attempted to treat themes of science subjects as learning materials for mathematics (Park, 2017). Traditionally, there have been attempts to integrate mathematics with science (Berlin, 1989; Kim \& Cho, 2015), as in the 'Continuum model' of Huntley (1998), but it has been pointed out that the order relation of what must be learned first is unknown (Suh et al, 2008). The current perception of convergence education related to mathematics is based on middle school and high school teachers (Kim, 2015; Kim \& Lee, 2013), and there have been no studies on elementary school teachers. In Korea, middle school and high school mathematics teachers only teach mathematics, but a single elementary school teacher teaches a variety of subjects, including mathematics. In this regard, it is necessary to investigate the perceptions of mathematics-focused STEAM education of elementary school teachers.

The purpose of this study is to ultimately discuss Korean STEAM education in a wide variety of subjects. In particular, we intend to discuss mathematics, which many have attempted to integrate with science but which has not been addressed as the main focus. This trend will eventually need to be discussed in other subjects beyond mathematics. Therefore, this study examines the teachers' understanding of not only STEAM education but also Math-Focused STEAM education.

\section{METHODOLOGY}

\section{Respondents}

In this study, 273 elementary teachers (female: 237, male: 35) of 24 public schools of Seoul and Gyunggido area in Korea participated in a questionnaire survey. In the case of Seoul, the questionnaire was distributed to at least one school in each of 11 education district offices belonging to Seoul city (See Table 1). A total of 288 copies of the questionnaire were distributed and 273 copies were collected, representing a recovery rate of $94.8 \%$. Table 2 shows the number of respondents' years of teaching experiences. 
Table 1. Distribution and collection of questionnaires

\begin{tabular}{|c|c|c|c|}
\hline District of school & School & Distribution & Collection \\
\hline \multirow{2}{*}{ Seoul \#1 } & $\mathrm{A}$ & 12 & 10 \\
\hline & $\mathrm{B}$ & 12 & 11 \\
\hline Seoul \#2 & C & 12 & 12 \\
\hline Seoul \#3 & $\mathrm{D}$ & 12 & 12 \\
\hline \multirow{3}{*}{ Seoul \#4 } & $\mathrm{E}$ & 12 & 12 \\
\hline & $\mathrm{F}$ & 12 & 12 \\
\hline & $\mathrm{G}$ & 12 & 11 \\
\hline \multirow{2}{*}{ Seoul \#5 } & $\mathrm{H}$ & 12 & 12 \\
\hline & 1 & 12 & 12 \\
\hline \multirow{2}{*}{ Seoul \#6 } & $\mathrm{J}$ & 12 & 12 \\
\hline & $\mathrm{K}$ & 12 & 12 \\
\hline \multirow{4}{*}{ Seoul \#7 } & $\mathrm{L}$ & 12 & 12 \\
\hline & $M$ & 12 & 12 \\
\hline & $\mathrm{N}$ & 12 & 12 \\
\hline & $\mathrm{O}$ & 12 & 12 \\
\hline \multirow{3}{*}{ Seoul \#8 } & $\mathrm{P}$ & 12 & 12 \\
\hline & $\mathrm{Q}$ & 12 & 9 \\
\hline & $R$ & 12 & 10 \\
\hline \multirow{2}{*}{ Seoul \#9 } & $\mathrm{S}$ & 12 & 11 \\
\hline & $T$ & 12 & 7 \\
\hline \multirow{2}{*}{ Seoul \#10 } & $U$ & 12 & 12 \\
\hline & $\mathrm{V}$ & 12 & 12 \\
\hline Seoul \#11 & W & 12 & 12 \\
\hline Gyunggido \#1 & $x$ & 12 & 12 \\
\hline Total & & 288 & 273 \\
\hline
\end{tabular}

Table 2. Respondents' of teaching experience years

\begin{tabular}{ccc}
\hline Range of teaching experience & $\mathbf{N}$ & $\%$ \\
\hline less than 5 years & 85 & 31.1 \\
\hline from 5 to 10 years & 63 & 23.1 \\
\hline from 11 to 15 years & 36 & 13.2 \\
\hline from 16 to 20 years & 30 & 11.0 \\
\hline more than 20 years & 55 & 20.1 \\
\hline No response & 4 & 1.5 \\
\hline Total & 273 & 100.0 \\
\hline
\end{tabular}

\section{Questionnaire}

The contents of the questionnaire were revised twice after a review by a STEAM education specialist, a current teacher, a teacher undergoing a doctoral course in elementary mathematics education, and three teachers undertaking master's courses. In the first review of the questionnaire, STEAM education was surveyed through analysis of related domestic and international research. From this research, the questionnaire was developed to include content on teachers' understanding of its necessity and effect of training. In the second review, the participants' response sections (items \# A-3, B-3, C-1, C-2\& C-3) were revised from multiple choice to 5-point Likert scale (from strongly disagree (1 point) to strongly agree $(5$ points)), while any duplicate items were deleted and other questions deemed necessary were added.

Three areas were modified and supplemented, as indicated in Table 3: (1) perception and experience of STEAM education, (2) perception and experience of Math-Focused STEAM education, and (3) problems of application and improvement direction of Math-Focused STEAM education application. 
Table 3. Items of questionnaire

\begin{tabular}{|c|c|c|}
\hline Strands & items & \# \\
\hline \multirow{4}{*}{$\begin{array}{l}\text { A. Perception and experience of } \\
\text { STEAM education }\end{array}$} & concept of 'convergence' & A-1 \\
\hline & perception of STEAM education by new model of education & $\mathrm{A}-2$ \\
\hline & perception of STEAM education ${ }^{*}$ & A-3 \\
\hline & STEAM extent of use in the field & A-4 \\
\hline \multirow{5}{*}{$\begin{array}{l}\text { B. Perception and experience of } \\
\text { Math-Focused STEAM education }\end{array}$} & experience of Math-Focused STEAM education & $\mathrm{B}-1$ \\
\hline & other suitable subjects for integration with Math-Focused STEAM education & B-2 \\
\hline & effectiveness of Math-Focused STEAM education ${ }^{*}$ & B-3 \\
\hline & materials for Math-Focused STEAM education & B-4 \\
\hline & lesson plan of Math-Focused STEAM education & B-5 \\
\hline \multirow{3}{*}{$\begin{array}{l}\text { C. Math-Focused STEAM education } \\
\text { problems of application and } \\
\text { improvement direction }\end{array}$} & ${\text { Expected difficulties in conducting Math-Focused STEAM education }{ }^{\star}}^{\star}$ & $\mathrm{C}-1$ \\
\hline & Expanding Support for Math-Focused STEAM education & $\mathrm{C}-2$ \\
\hline & Tasks needed to activate Math-Focused STEAM education ${ }^{*}$ & $\mathrm{C}-3$ \\
\hline
\end{tabular}

${ }^{*} 5$ Likert-Scale

The data collected in this study were compared according to frequency, response, tendency, percent, and mean based on the SPSS 24.0 program. A Pearson test and $\chi^{2}$ tests were carried out to confirm correlation between items, and simple regression analysis was used for causality analysis.

\section{FINDINGS}

\section{Elementary Teachers' Perception of STEAM Education}

In the question regarding the teachers' understanding of the meaning of 'convergence' in STEAM education, of the total 273 questionnaires, 260 were analyzed and classified, except for 13 cases (See Table 4).

Table 4. Elementary teachers' perception of 'convergence' (A-1): How do think of the meaning of 'convergence' in STEAM education?

\begin{tabular}{llcc}
\hline & Response Type & $\mathbf{N}$ & \% \\
\hline \multirow{2}{*}{ dictionary definition of convergence } & integrated approach & 94 & 34.1 \\
\cline { 2 - 4 } & convergent approach & 36 & 13.0 \\
\hline integration with real life & & 19 & 6.9 \\
\hline \multirow{2}{*}{ education for higher thinking* } & creativity & 16 & 5.8 \\
\cline { 2 - 4 } & problem solving & 15 & 5.4 \\
\cline { 2 - 4 } & comprehensive thinking & 15 & 5.4 \\
\hline Overall information about STEAM & & 18 & 17.5 \\
\hline Subject-centered integration & 49 & 0.4 \\
\hline Others & 1 & 13 & 4.7 \\
\hline no response & 276 & 100.0 \\
\hline Total & & &
\end{tabular}

In the case of suggesting a lexical meaning for the term 'convergence', the respondents were given a choice between 'integrated approach' (which implies 'combining various fields' for a 'convergent approach') and 'the integrated approach is a new concept'. In the questionnaire response, if the respondent considered integration to be a new concept, then the response was classified as 'convergent approach'.

Conversely, if it means that it is a sum mainly even the word 'convergence' is used, then the response was classified to 'integrated approach'. The result of the classification showed that of the total responses, in 130 (50\%), the teacher understood the dictionary meaning. Of these 130 responses, 94 integrated approaches (34.1\%) and 36 integrated approaches (13.0\%) account for more than one integrated approach. In other words, teachers often perceive convergence as 'combining specific subjects, knowledge, and functions'. On the other hand, they also recognized convergence as 'combining new subjects with academic subjects, knowledge, and functions, or applying them'.

Investigation into whether STEAM education is recognized as a new education model (A-2) showed that 99 teachers $(37 \%)$ believed that STEAM education differed from the existing education, whereas 170 teachers $(63 \%)$ believed that STEAM education did not significantly differ from the existing education. The questionnaire included a question on whether the teacher fully understands the meaning of 'STEAM education', and their general perception of the effectiveness and necessity of STEAM education using the 5-step scale (See Table 5). 
Table 5. Elementary teachers' perception of STEAM education (A-3)

\begin{tabular}{clcc}
\hline item & Item Contents & M & SD \\
\hline 1 & I fully understand STEAM education. & 3.42 & 0.81 \\
\hline 2 & STEAM education is needed in elementary school. & 4.10 & 0.66 \\
\hline 3 & STEAM education is student-centered education. & 4.07 & 0.69 \\
\hline 4 & STEAM education is helpful for creativity. & 4.31 & 0.64 \\
\hline 5 & STEAM education helps to improve problem solving ability. & 4.34 & 0.65 \\
\hline 6 & STEAM education helps in cooperative thinking. & 4.22 & 0.74 \\
\hline 7 & STEAM education improves real life application ability. & 4.37 & 0.62 \\
\hline 8 & STEAM education increases interest in the subject. & 4.15 & 0.72 \\
\hline
\end{tabular}

The lowest average score was 3.42, for the question on whether they understood STEAM education sufficiently. The difference in responses among the teachers was significant because the standard deviation was higher than in other items. The responses from teachers who viewed 'convergence' in STEAM education as 'connection/integration with real life' showed the highest average score of 4.37 in terms of improving the applicability of real-life applications. Many teachers were aware that STEAM education would help to enhance mathematics, core competencies, and advanced thinking skills.

Questionnaire (A-4) was designed to determine how STEAM education was performed at the elementary school level (redundant response possible) after the strengthening of the STEAM education policies since 2011 (See Table 6). 104 teachers $(29.4 \%)$ responded that 'only some interested teachers use the STEAM education approach'. Moreover, 83 teachers $(23.4 \%)$ responded that STEAM education has only been conducted in research schools and not in general schools.

Table 6. Whether STEAM education is well applied in the field (A-4)

\begin{tabular}{clcc}
\hline item & Item Contents & $\mathbf{N}$ & $\%$ \\
\hline 1 & Most teachers use STEAM in at least one class. (Well utilized). & 18 & 5.1 \\
\hline 2 & Only some interested teachers use the STEAM education approach. & 104 & 29.4 \\
\hline 3 & I teach class by the meeting of the same grade teachers' discussion. & 16 & 4.5 \\
\hline 4 & I sometimes observe STEAM used in public classes. & 70 & 19.8 \\
\hline 5 & I have seen STEAM used in schools that have a particular purpose, such as in research schools. & 83 & 23.4 \\
\hline 6 & STEAM only exists formally in the school curriculum. & 49 & 13.8 \\
\hline 7 & STEAM is not present in the school curriculum. & 8 & 2.3 \\
\hline 8 & others & 6 & 1.7 \\
\hline & & Total & 354 \\
\hline
\end{tabular}

\section{Elementary Teachers' Perception of STEAM Education on Mathematics}

Based on the basic perception of STEAM education, we examined the elementary teachers' perceptions of MathFocused STEAM education. First, unlike conventional science-based STEAM education, we examined subjects for convergence with mathematics in classroom setting. The effectiveness of Math-Focused STEAM education was investigated using the Likert-scale. We also investigated the materials and application methods needed to increase the use of Math-Focused STEAM education in the field.

Of the total 273 respondents, 138 (50.5\%) had experience and 135 (49.5\%) had no experience (B-1) in MathFocused STEAM education. This is because the existing STEAM education is mainly comprised of science, so 'STEAM education based on mathematics' is unfamiliar. Table 7 shows the teachers' responses to the question on the subjects they perceived to be easy to integrate with 'mathematics' when Math-Focused STEAM education is employed (B-2).

Table 7. Easy subjects for convergence with mathematics in order to apply STEAM education (B-2)

\begin{tabular}{lccccc}
\hline Subject & $\mathbf{N}$ & \% & Subject & $\mathbf{N}$ & \% \\
\hline Korean & 65 & 9.1 & Physical Education & 45 & 6.3 \\
\hline Social studies & 78 & 10.9 & Music & 71 & 9.9 \\
\hline Moral education & 13 & 1.8 & Fine arts & 140 & 19.6 \\
\hline Science & 217 & 30.3 & English & 13 & 1.8 \\
\hline Practical arts & 73 & 10.2 & & & 100.0 \\
\hline
\end{tabular}

The item of science $(\mathrm{N}=217,30.3 \%)$ had the highest rate, with 715 responses. This is because mathematics and science subjects are similar in terms of academic characteristics, as listed below: 
Science and math both are subjects having an instrumental nature.

Logical thinking is needed.

Science and math involve essential skills for the future.

Science directly involves mathematical concepts.

Science and math are readily applied in real life.

The arts curriculum showed the second highest rate $(\mathrm{N}=140,19.6 \%)$. This is because the art subject uses mathematical principles in aesthetic concepts such as composition, proportion, regularity, and geometry. Moreover, these responses showed that the teachers considered geometrical concepts such as geometric shapes as both mathematical concepts and aesthetic elements used in art.

Social studies was ranked third highest in terms of its ability to be integrated with mathematics ( $N=78,10.9 \%)$. This is because mathematics is used as a tool in analyzing data in the social sciences and mathematical concepts are often used in economics. Social studies were followed by practical arts, then music, Korean, and finally physical education.

Four teachers selected all subjects as being readily able to be integrated with mathematics for the following reasons:

The subjects have commonalities and the benefit of integration will increase.

A teacher can selectively combine or disassociate subjects according to their learning goals, teaching methods, or learning topics.

Of course, all courses can be fused together.

All studies include pattern, number, figures, etc., all of which are fundamental in mathematics.

Similar to the perception that STEAM education represents the 'convergence' of technology, engineering, arts, and mathematics, 'convergence' can also represent the integration of science, fine arts, practical arts, technology, and engineering.

Most of the items related to the effectiveness of Math-Focused STEAM education were found to have an average of 4 points or more. This means that most teachers perceive Math-Focused STEAM education as relatively positive (See Table 8). Among the effectiveness of Math-Focused STEAM education, the item, 'Experience problems related to real life' showed the highest score $(\mathrm{m}=4.33)$. This shows the possibility that Math-Focused STEAM education can be seen as addressing common problems in the field of mathematics education such as 'It is difficult to apply in real life because it is not embodied in my understanding.'

Table 8. Effectiveness of Math-Focused STEAM Education (B-3)

\begin{tabular}{|c|c|c|c|}
\hline Item & Item Contents & $\mathbf{M}$ & SD \\
\hline 1 & It is necessary in education in elementary school. & 4.04 & 0.74 \\
\hline 2 & It will increase my interest in mathematics. & 4.16 & 0.74 \\
\hline 3 & It will have a positive impact on the perception of the value of mathematics. & 4.14 & 0.75 \\
\hline 4 & It will have a positive impact on improving confidence in math. & 3.90 & 0.84 \\
\hline 5 & It will improve cooperative problem solving. & 4.14 & 0.69 \\
\hline 6 & It will improve mathematical communication skills. & 4.25 & 0.79 \\
\hline 7 & It will help you understand mathematical concepts. & 4.04 & 0.73 \\
\hline 8 & It will help improve creative thinking. & 4.24 & 0.73 \\
\hline 9 & It will help improve math academic achievement. & 3.79 & 0.84 \\
\hline 10 & It provides experience with problems related to real life. & 4.33 & 0.69 \\
\hline 11 & It can lead to learner-centered activities. & 4.22 & 0.73 \\
\hline 12 & $\begin{array}{l}\text { Knowledge acquired through embodiment of understanding can be manifested through concrete } \\
\text { activities. }\end{array}$ & 4.08 & 0.79 \\
\hline
\end{tabular}

Teachers' perceptions of materials suitable for Math-Focused STEAM education and how to use them were investigated (See Table 9). The result suggested that teachers ( $\mathrm{N}=131,48.0 \%)$ relied the most on the item, 'I can bring materials (materials) for classes even if they are not in textbooks or curriculum'. 
Table 9. Materials of Math-Focused STEAM education (B-4)

\begin{tabular}{|c|c|c|c|}
\hline \multicolumn{2}{|r|}{ Item Item Contents } & \multirow{2}{*}{$\begin{array}{l}\mathbf{N} \\
20\end{array}$} & \multirow{2}{*}{$\begin{array}{c}\% \\
7.3 \\
\end{array}$} \\
\hline 1 & The grade is not critical but tests must utilize the materials presented in the course. & & \\
\hline 2 & Materials need to be integrated according to the grade level. & 86 & 31.5 \\
\hline 3 & Even if a material is not mentioned in a textbook or the curriculum, it can be utilized in the class. & 131 & 48.0 \\
\hline 4 & The concept of learning is more important than the source or type of material used. & 34 & 12.5 \\
\hline 5 & other & 2 & 0.7 \\
\hline \multicolumn{2}{|r|}{ Total } & 273 & 100.0 \\
\hline
\end{tabular}

The result of responses to the instruction style of Math-Focused STEAM education (See Table 10) showed that the item with the highest score $(\mathrm{N}=198,72.5 \%)$ was 'Math-Focused STEAM education should be delivered by deepening learning according to the concept application level after learning about the concept'. This means that most of the teachers consider the basic concepts necessary for learning should precede more specific learning in each subject, and it should be delivered in an intensive way that uses these concepts in STEAM education.

\begin{tabular}{|c|c|c|c|}
\hline item & Item Contents & $\mathbf{N}$ & $\%$ \\
\hline 1 & It should be delivered from the introduction of the unit to the end of the unit. & 30 & 11.0 \\
\hline 2 & $\begin{array}{l}\text { It should be delivered by deepening learning according to the concept application level after learning } \\
\text { about the concept. }\end{array}$ & 198 & 72.5 \\
\hline 3 & $\begin{array}{l}\text { It should also be undertaken while students are performing creative experiential activities outside of the } \\
\text { course time. }\end{array}$ & 12 & 4.4 \\
\hline 4 & After completing the instruction plan given for each semester and grade, it is not related to evaluation. & 27 & 9.9 \\
\hline \multirow{2}{*}{\multicolumn{2}{|c|}{5 other }} & 6 & 2.2 \\
\hline & & 273 & 100 \\
\hline
\end{tabular}

\section{Problems of Application and Improvement Direction of Math-Focused STEAM Education}

The result of the questionnaire (See Table 11) related to the difficulties expected when applying mathematics in education shows that teachers consider the most critical difficulty to be 'requiring a significant amount of preparation time' $(\mathrm{m}=4.42)$. Following that, difficulties with 'insufficient guide and materials' $(\mathrm{m}=4.37)$, 'lack of time to apply' $(\mathrm{m}=4.19)$, and 'insufficient classroom budget' $(\mathrm{m}=4.18)$ were relatively large as well. The teachers were expected to be burdened in all areas from the design of the lesson plan to the application of the lesson plan. The successful nature of Math-Focused STEAM education implies that teachers need to reduce the burden of preparing for classes. In addition, teachers showed an overall lack of understanding of Math-Focused STEAM education $(\mathrm{m}=4.08)$. In contrast, it can be seen that 'the relation between mathematics and other subjects is relatively less difficult' $(m=3.73)$, 'less stressed on students' $(m=3.34)$, and 'positive to students' $(m=3.38)$. The lack of understanding of Math-Focused STEAM education seems to be inconsistent with the practical experience.

Table 11. Problems of applying Math-Focused STEAM education in the classroom (C-1)

\begin{tabular}{|c|c|c|c|}
\hline item & Item Contents & M & SD \\
\hline 1 & Teachers generally show a lack of understanding of Math-Focused STEAM education. & 4.08 & 0.75 \\
\hline 2 & Insufficient textbooks and materials are available to inform teachers on the method of application. & 4.37 & 0.71 \\
\hline 3 & It is difficult to associate mathematics with other subjects. & 3.73 & 0.88 \\
\hline 4 & A large amount of preparation time is needed. & 4.42 & 0.68 \\
\hline 5 & The funds required such as dioceses grants for supplies are insufficient. & 4.18 & 0.90 \\
\hline 6 & It is difficult to secure sufficient time for application. & 4.19 & 0.93 \\
\hline 7 & It is difficult to conduct evaluation. & 3.75 & 1.06 \\
\hline 8 & Students are burdened with excessive workload. & 3.34 & 1.08 \\
\hline 9 & It only has a positive impact on some students. & 3.38 & 1.08 \\
\hline 10 & $\begin{array}{l}\text { The teaching skills necessary for integrating classes is insufficient (project-based instruction, discussion } \\
\text { investigation etc.). }\end{array}$ & 3.95 & 0.90 \\
\hline
\end{tabular}

178 teachers $(65.2 \%)$ stated that they would implement Math-Focused STEAM education if more support was provided (See Table 12). This means that Math-Focused STEAM education can be applied in other subjects through the expansion of support systems. Each item related to the need for further support for the activation of MathFocused STEAM education scored more than 4 points (See Table 13). It can be seen that the teachers feel that supportive measures need to be made available in the actual school context. 
Table 12. Expanding Support for Math-Focused STEAM education (C-2) $(\mathrm{N}, \%)$

\begin{tabular}{lcccc}
\hline Item Contents & $\begin{array}{c}\text { Strongly } \\
\text { agree }\end{array}$ & agree & $\begin{array}{c}\text { moderate } \\
\text { disagree } \\
\text { disagree }\end{array}$ \\
\hline If the support plan is expanded, do you intend to & 49 & 129 & 75 & 15 \\
implement Math-Focused STEAM education in the future? & $(17.9)$ & $(47.3)$ & (27.5) & (5.5) \\
\hline
\end{tabular}

Table 13. Need for Activation of Math-Focused STEAM Education (C-3)

\begin{tabular}{clcc}
\hline item & Item Contents & M & SD \\
\hline 1 & It is reflected the competence of convergence in curriculum revision and textbook development. & 4.15 & 0.73 \\
\hline 2 & It is perceived that the classroom-centered instruction needs to change. & 4.24 & 0.78 \\
\hline 3 & $\begin{array}{l}\text { Various instructional skills and experience (or training) is needed for the teacher to integrate } \\
\text { mathematics with other subjects. }\end{array}$ & 4.25 & 0.70 \\
\hline 4 & Provide clear guidelines on the delivery of the curriculum and instruction. & 4.25 & 0.76 \\
\hline 5 & Provide teacher training for Math-Focused STEAM Education. & 4.18 & 0.78 \\
\hline 6 & Provide textbooks and materials related to Math-Focused STEAM Education & \\
\hline 7 & Applicable methods for students need to be given at various levels. & & 4.48 \\
\hline 8 & Schools need to support classroom research. & 0.66 \\
\hline 9 & Obtain funding for the purchase of mathematics teaching materials and supplies. & 4.46 & 0.65 \\
\hline 10 & Reduce administrative tasks. & 4.08 & 0.83 \\
\hline
\end{tabular}

\section{Effects of the Teachers' Expectations of Implementation of Embodied Cognition on the Awareness of Teacher's Math-Focused STEAM Education}

STEAM education reflects the changes of the times and aims to help students learn knowledge in various environments in an integrated way. This view is also consistent with embodied cognition. As a follow-up study, this study attempts to link STEAM education with the perspective of embodied cognition. When taking in knowledge, not only is the knowledge itself important, but the relevance of the human body and the environment are important as well. This change has accelerated the shift toward the ability to acquire knowledge in a variety of ways, rather than simply acquiring knowledge in the traditional way.

In order to investigate the awareness of teacher's STEAM education and the effectiveness of Math-Focused STEAM education on the expectations for implementation of embodied cognition ( $<\mathrm{B}-3>\# 12)$, multiple regression analysis was performed (See Table 14). The result showed that two items (\#7 \& \#8) of <A-3> and five items (\#1, $\# 2, \# 5$, \#9, and \#11) of <B-3> affect the expectation of implementation of embodied cognition.

Table 14. Teachers' expectations of implementation of embodied cognition on the effect of their awareness of Math-Focused STEAM education

\begin{tabular}{|c|c|c|c|c|c|c|}
\hline Independent variables & $\boldsymbol{b}$ & $\boldsymbol{\beta}$ & $\boldsymbol{t}$ & $p$ & $R^{2}$ & $F\left(d f_{1}, d f_{2}\right)$ \\
\hline $\begin{array}{l}\text { Contribution of convergence education to real life adaptation } \\
\text { (A-3 \#7) }\end{array}$ & .15 & .12 & $2.06^{*}$ & .040 & \multirow{7}{*}{.70} & \multirow{7}{*}{$\begin{array}{l}F= \\
29.81^{\star * *} \\
(19,249)\end{array}$} \\
\hline $\begin{array}{l}\text { Interest in the curriculum of convergence education } \\
\text { (A-3\#8) }\end{array}$ & -.14 & -.12 & $-2.50^{*}$ & .013 & & \\
\hline $\begin{array}{l}\text { The need for Math-Focused STEAM education } \\
(B-5 \# 1)\end{array}$ & -.15 & -.14 & $-2.43^{*}$ & .016 & & \\
\hline $\begin{array}{l}\text { Contribution of Math-Focused STEAM education to increase students' } \\
\text { interest in mathematics } \\
\text { (B-5\#2) }\end{array}$ & .17 & .16 & $2.34^{*}$ & .020 & & \\
\hline $\begin{array}{l}\text { Contribution of Math-Focused STEAM education to improve cooperative } \\
\text { problem-solving ability } \\
\text { (B-5 \#5) }\end{array}$ & .20 & .19 & $2.67 \star \star$ & .008 & & \\
\hline $\begin{array}{l}\text { Contribution of Math-Focused STEAM education to improve mathematics } \\
\text { academic achievement } \\
\text { (B-5 \#9) }\end{array}$ & .13 & .14 & $2.50^{*}$ & .013 & & \\
\hline $\begin{array}{l}\text { Inducing learner-centered activities of Math-Focused STEAM education } \\
(B-5 \# 11)\end{array}$ & .33 & .30 & $5.09^{\star \star *}$ & .000 & & \\
\hline
\end{tabular}

\section{DISCUSSION AND CONCLUSIONS}

The purpose of this study was to investigate elementary school teachers' perceptions on the status of MathCentered STEAM education as basic research for exploring the possibility of integration between science and 
knowledge. This study is motivated by the recognition for the need to enhance creativity in applying mathematics since the recent changes made to the 2015 Revised National Curriculum aimed at Fostering Creative-Convergence Human Resource in Korea.

(1) Teachers tended to perceive 'convergence' in STEAM education as either an 'integrated approach' whereby particular subjects or topics are taught together, or as a 'convergent approach' to teach together. Elementary teachers recognized that STEAM education is not a new type of education, but simply provides a name for the existing education methods. The teachers expressed positive responses towards the educational effectiveness and necessity of STEAM education on students. These points indicate that there is room for STEAM education to be fully utilized in various subjects. However, as STEAM education was introduced in 2011, the fact that STEAM education is still not widespread in schools indicates that teachers recognize it as an existing problem (Sim, Lee, \& Kim, 2015). In particular, since the Department of Science has dealt with STS and STEAM, it is a matter of concern that there appears to be little effort toward apply STEAM education in other subjects.

(2) Unlike the existing STEAM education, some teachers did not yet have access to Math-Focused STEAM education. This is because the training is organized in various forms by level, but is composed mainly of the content of science subjects (Lee, Park, \& Kim, 2013). In Korea, most STEAM education programs and the training that most teachers receive specifically involve Science-Focused STEAM education. However, most teachers responded positively to the effectiveness and necessity of Math-Centered STEAM education. Regarding the materials required for applying Math-Centered STEAM education, the teachers showed an open attitude, suggesting they were not bound to textbooks or curriculum. A positive correlation was shown between the perception of Math-Centered STEAM education and the effectiveness of Math-Centered STEAM education.

(3) The 'creative/convergence' capability mentioned in the 2015 revised curriculum has thus far failed to materialize (MOE, 2015). The most salient problems recognized by most teachers for the application of MathFocused STEAM education to the classroom are the time required for preparing lessons for classes and the lack of related textbooks and materials. Despite the fact that the current curriculum is related to ability, there is little data on what ability is in mathematics and how to develop it. Development and application studies have begun among researchers, but there are still insufficient resources for field application. However, in cases where supportive systems had been expanded, most of the respondents were positive about conducting Math-Focused STEAM education. Considering this, it is necessary to focus on and improve Math-Focused STEAM education linked to the curriculum.

The teaching of mathematics for future education should be discussed in a meaningful context (Nemirovsky \& Ferrara, 2009; Nunez, Edwards, \& Matos, 1999). This requires the integration of various experiences, integrated learning through active cognitive processes (Osgood-Campbell, 2015; Stolz, 2015), and various connections (Berlin \& White, 1995; NCTM, 1989). The results of this study reaffirm the pedagogical concept that learning must be carried out through actual experience (Morrison, Ross, \& Kemp, 2004). The implications for the successful implementation of Math-Focused STEAM education in the future are as follows.

It is necessary to implement a training program that will develop practical and professional expertise in relation to Math-Focused STEAM education. The teachers' perceptions of Math-Focused STEAM education will then be improved. It is possible to improve the quality of education by developing the convergence of subjects through training and realizing the practical application. Therefore, it is necessary to create an environment that is easy to apply in reality, and to further develop and disseminate teaching materials, activities, and exemplars that teachers can actually apply in the field. In Korea, the curriculum is developed and operated by the nation. In this respect, it will be necessary to reorganize and expand the STEAM training system which is currently mainly carried out in the science education department. It is necessary to reorganize the contents of the training so that various subjects can be centered, or to have practical training that enables various subjects to be connected according to the interest of the teacher.

In addition, the budgets for current science subjects are separately organized, but the budgets for mathematics subjects are not separately organized. In order to be able to teach in a variety of forms, substantial amounts of support will be necessary so as to create a physical education environment. It will be necessary to have a realistic plan to make separate budgets for STEAM education, rather than only having a separate budget for science, so that budgets can be used throughout various subjects. It is also important to give practical advice on how to secure class time, not just to emphasize the discretion of teachers.

In-depth analysis is needed to evaluate the educational effects of Math-Focused STEAM education through the development and application of the teaching and learning processes, and to achieve positive results in fostering students' convergent thinking, creative thinking, and positive attitudes toward mathematics. As mentioned earlier, substantial research is needed on the meaning of 'creativity-convergence' in mathematics and how to implement it. We should particularly focus on what impact Math-Focused STEAM education has on students, what it should focus on, and what differentiates it from other types of STEAM education. 
In this study, the teachers' perceptions showed that teachers' motivation and opportunities need to improve in order improve their perception of the need for and effect of Math-Focused STEAM education. Furthermore, various improvements are needed to carry out Math-Focused STEAM education in the field. Through this study and subsequent studies, it will be possible to increase the application of Math-Focused STEAM education in the field, and thus to extend the knowledge embodied in the mathematics subject.

\section{ACKNOWLEDGEMENTS}

This work was supported by the Ministry of Education of the Republic of Korea and the National Research Foundation of Korea (NRF-2016S1A5A2A01022028).

\section{REFERENCES}

Askhamov, A. A., Konysheva, A. V., \& Gapsalamov, A. R. (2016). Use of e-resources of the learning environment in teaching mathematics to future engineers. International Journal of Environmental and Science Education, 11(5), 673-684. https:// doi.org/10.12973/ijese.2016.340a

Baek, Y. S., Park, H. J., Kim, Y. M., Noh, S. G., Park, J., Lee, J. Y., Jung, J. S., Choi, Y. H., \& Han, H. S. (2011). STEAM education in Korea [in Korean with English abstract]. The Journal of Learner-Centered Curriculum and Instruction, 11(4), 149-171.

Berlin, D. F. (1989). The integration of science and mathematics education: Exploring the literature. School Science and Mathematics, 59(1), 73-80. https://doi.org/10.1111/j.1949-8594.1989.tb11892.x

Berlin, D. F., \& White, A. L. (1995). Connecting school science and mathematics. In P. A. House \& A. F. Coxford (Eds.), Connecting mathematics across the curriculum (pp.22-33). Reston: NCTM.

Chae, H. I., \& Noh, S. G. (2015). Analysis of elementary school teachers' innovation configuration on STEAM [in Korean with English abstract]. Journal of Science Education, 39(1), 44-57. https://doi.org/10.21796/jse.2015.39.1.44

FitzSimons, G. E., \& Boistrup, L. B. (2017). In the workplace mathematics does not announce itself: Towards overcoming the hiatus between mathematics education and work. Educational Studies in Mathematics, 95(3), 329-349. https:/ / doi.org/10.1007/s10649-017-9752-9

Gresnigt, R., Taconis, R., Keulen, H., Gravemeijer, L., \& Baartman, L. (2014). Promoting science and technology in primary education: A review of integrated curricula. Studies in Science Education, 50(1), 47-84. https:// doi.org/10.1080/03057267.2013.877694

Han, H. J., \& Kwon, S. H. (2017). An analysis of content and convergence method of scientific technology and humanities in elementary school STEAM programs [in Korean with English abstract]. Journal of the Korean Association for Science Education, 37(2), 313-322. https:/ / doi.org/10.14697/jkase.2017.37.2.0313

Han, H. S., \& Lee, H. J. (2012). A study on the teachers' perceptions and needs of steam education [in Korean with English abstract]. Journal of Learner-Centered Curriculum and Instruction, 12(3), 573-603.

Hennessy, S. (2006). Integrating technology into teaching and learning of school science: A situated perspective on pedagogical issues in research. Studies in Science Education, 42, 1-50. https:/ / doi.org/10.1080/03057260608560219

Huntley, M. A. (1998). Design and implementation of a framework for defining integrated mathematics and science education. School Science and Mathematics, 98(6), 320-327. https://doi.org/10.1111/j.19498594.1998.tb17427.x

Hwang, S. W., Kim, N. J., Son, J. S., Song, W. H., Lee, K. J., Choi, S. J., \& Lew, K. H. (2017). Development and effectiveness of STEAM outreach program based on mathematics [in Korean with English abstract]. Communications of Mathematical Education, 31(4), 389-407. https:/ / doi.org/10.7468/jksmee.2017.31.4.389

Ju, M. K., Song, R. J., \& Moon, J. E. (2013). Inquiry into how to practice yungbokhap education in mathematics: An analysis of focus group interview with school mathematics teachers [in Korean with English abstract]. Journal of Learner-Centered Curriculum and Instruction, 13(4), 437-467.

Jung, J. H., Jeon, J. D., \& Lee, H. N. (2015). Domestic and international experts' perception of policy and direction on STEAM education [in Korean with English abstract]. Journal of Science Education, 39(3), 358-375. https:/ / doi.org/10.21796/jse.2015.39.3.358

Kang, K. W. (2015). The exploration of the origin, transition, background, and identity of STEAM education [in Korean with English abstract]. The Journal of the Korean Society for the Gifted and Talented, 15(2), 5-29. 
Kim, D. H. (2017). TPACK as a research tool for technology integration into classroom: A review of research trends in Korea [in Korean with English abstract]. The Journal of Elementary Education, 30(4), 1-22. https://doi.org/10.29096/JEE.30.4.01

Kim, H. J. (2015). A study on the mathematics teachers' perception of STEAM education (Unpublished master's thesis) [in Korean with English abstract]. Dankook University, Gyeonggi, Korea.

Kim, M. K., \& Cho, M. K. (2015). Design and implementation of integrated instruction of mathematics and science in Korea. Eurasia Journal of Mathematics, Science $\mathcal{E}$ Technology Education, 11(1), 3-15. https://doi.org/10.12973/eurasia.2015.1301a

Kim, R. Y., \& Lee, M. H. (2013). A study on the perception and competence of pre-service teachers and in-service teachers for the integrated mathematics curriculum (in Korean). Proceedings of the KSME 2013 Spring Conference on Mathematics Education, 147-152.

Kwon, N. J., \& Ahn, J. H. (2012). The analysis on domestic research trends for convergence and integrated science education [in Korean with English abstract]. Journal of the Korean Association for Research in Science Education, 32(2), 265-278. https:/ / doi.org/10.14697/jkase.2012.32.2.265

Kwon, N. J., \& Na, S. H. (2010). Investigation on the feasibility and the status of elementary convergence science education [in Korean with English abstract]. Studies on Constitutional Cases, 23, 65-75.

Lee, J. H., \& Yoon, M. B. (2014). The development of STEAM education material focused on elementary mathematics using architectures [in Korean with English abstract]. Journal of the Korea Contents Association, 14(6), 499-512. https:/ / doi.org/10.5392/JKCA.2014.14.06.499

Lee, J. W., Park, H. J., \& Kim, J. B. (2013). Primary teachers' perception analysis on development and application of STEAM education program [in Korean with English abstract]. Journal of Korean Elementary Science Education, 32(1), 47-59.

Lee, K. J., \& Kim, K. J. (2012). Exploring the meanings and practicability of Korea STEAM education [in Korean with English abstract]. The Journal of Elementary Education, 25(3), 55-81.

Lim, C. H., \& Oh, B. J. (2015). Elementary pre-service teachers and in-service teachers' perceptions and demands on STEAM education [in Korean with English abstract]. Journal of Korean Society of Earth Science Education, 8(1), 1-11. https:/ / doi.org/10.15523/JKSESE.2015.8.1.1

Lim, S. M., Kim, Y. S., \& Lee, T. S. (2014). Analysis of elementary school teachers' perception on field application of STEAM education [in Korean with English abstract]. Journal of Science Education, 38(1), 133-143. https://doi.org/10.21796/jse.2014.38.1.133

Ministry of Education [MOE]. (2015). The general guideline of the national curriculum (in Korean). Seoul: The Ministry of Education.

Morrison, G. R., Ross, S. V., \& Kemp, J. E., (2004). Designing effective instruction. New York: John Wiley \& Sons.

Na, G. S., Park, M. M., Kim, D. W., Kim, Y., \& Lee, S. J. (2018). Exploring the direction of mathematics education in the future age [in Korean with English abstract]. Journal of Educational Research in Mathematics, 28(4), 437478. https:// doi.org/10.29275/jerm.2018.11.28.4.437

National Council of Teachers of Mathematics [NCTM]. (1989). Curriculum and evaluation standards for school mathematics. Reston: NCTM.

Nemirovsky, R., \& Ferrara, F. (2009). Mathematical imagination and embodied cognition. Educational Studies in Mathematics, 70(2), 159-174. https:/ / doi.org/10.1007/s10649-008-9150-4

Noh, D. W., Kim, S. B., Yeom, M. G., Lee, S. Y., \& Kim, S. H. (2018). Seeking the solutions to realize interdisciplinary education for the era of fourth industrial revolution [in Korean with English abstract]. Journal of Education Science, 21(2), 145-167.

Nunez, R. E., Edwards, L. D., \& Matos, J. F. (1999). Embodied cognition as grounding for situatedness and context in mathematics education. Educational Studies in Mathematics, 39(1), 45-65. https:/ / doi.org/10.1023/ A:1003759711966

OECD (2003). Definition and selection of key competencies: executive summary. Retrieved from http://www.oecd.org/pisa/35070367.pdf

Oh, C. S. (2018). Analysis on effect of convergence education program as education plan to prepare the fourth industrial revolution era [in Korean with English abstract]. The Journal of Educational Research, 32(2), 23-58.

Osgood-Campbell, E. (2015). Investigating the education implications of embodied cognition: A model interdisciplinary inquiry in mind, brain, and education curricula. Mind, Brain, and Education, 9(1), 3-9. https://doi.org/10.1111/mbe.12063 
Park, H. S. (2017). Analysis on the development of integrated teaching-learning materials of the mathematics and other subjects [in Korean with English abstract]. Journal of the Korea Convergence Society, 8(7), 331-339. https:/ / doi.org/10.15207/JKCS.2017.8.7.331

Pavlekovic, M., Kolar-Begovic, Z., \& Kolar-Super, R. (2013). Mathematics teaching for the future. Josip Juraj Strossmayer University of Osijekg faculty of Teacher Education and Department of Mathematics [monograph]. Retrieved from http:/ / search.proquest.com.ssl.access.ewha.ac.kr/docview /1373086171?accountid=10785

Rennie, L., Venville, G., \& Wallace, J. (Eds.). (2012). Integrating science, technology, engineering, and mathematics: Issues, reflections, and ways forward (pp. 1-11). London: Routledge. https:/ / doi.org/10.4324/9780203803899

Rhie, D. H., Kim, J. O., \& Kim, J. S. (2015). Development and application of STEAM education process model for the 'creative design' step of STEAM learning criteria [in Korean with English abstract]. Korean Technology Education Association, 15(1), 150-170.

Ryu, S. R., Lee, J. H., Yoon, M. B., Kim, H. S. (2018). Development of convergence education program for elementary school gifted education based on mathematics and science [in Korean with English abstract]. Journal of the Korea Convergence Society, 9(10), 217-228. https:/ / doi.org/10.15207/JKCS.2018.9.10.217

Shin, J. H. (2013). Survey of primary \& secondary school teachers' recognition about STEAM convergence education [in Korean with English abstract]. The Korean Journal of the Learning Sciences, 7(2), 29-53.

Shin, M. S. (2018). A meta-analysis of the effects of STEAM education program [in Korean with English abstract]. The Journal of Learner-Centered Curriculum and Instruction, 18(11), 345-363. https:// doi.org/10.22251/jlcci.2018.18.11.345

Shin, Y. J., \& Han, S. K. (2011). A study of the elementary school teachers' perception in STEAM education [in Korean with English abstract]. Journal of Korean Elementary Science Education, 30(3), 514-523.

Sim, J. H., Lee, Y. R., \& Kim, H. K. (2015). Understanding STEM, STEAM Education, and addressing the issues facing STEAM in the Korean context [in Korean with English abstract]. Journal of the Korean Association for Science Education, 35(4), 709-723. https:/ / doi.org/10.14697/jkase.2015.35.4.0709

Son, Y. A., Jung, S. I., Kwon, S. K., Kim, H. W., \& Kim, D. R. (2012). Analysis of prospective and in-service teachers' awareness of STEAM convergent education [in Korean with English abstract]. Institute for Humanities and Social Sciences, 13(1), 255-284. https:/ / doi.org/10.15818/ihss.2012.13.1.255

Stolz, S. A. (2015). Embodied learning. Educational Philosophy and Theory, 47(5), $474-487$. https:/ / doi.org/10.1080/00131857.2013.879694

Suh, B. E., Kim, H. K., Kim, J. Y., Kim, J. J., Kim, H. J., \& Chae, J. L. (2008). The analysis of the tendency that the understanding of mathematics affects the learning of science and the research on the connection between the two subjects [in Korean with English abstract]. Journal of the Korean School Mathematics Society, 11(4), 677694.

Woo, J. H., \& Yoo, M. H. (2013). Analysis of the cases in elementary STEAM programs convergence and integration type for the gifted [in Korean with English abstract]. Korean Science Education Society for the Gifted, 5(2), 8295.

Yigit, M. (2014). A review of the literature: How pre-service mathematics teachers develop their technological, pedagogical, and content knowledge. International Journal of Education in Mathematics, Science and Technology, 2(1), 26-35. https://doi.org/10.18404/ijemst.96390

\section{http://www.ejmste.com}

